\title{
ZU GOLDSMITHS VICAR OF WAKEFIELD.
}

Eine ende 1903 erschienene berliner dissertation über den Vicar of Wakefield ') veranlasst mich, noch einmal das wort zu ergreifen. Der verfasser bemerkt in der einleitung, dass seine arbeit beim erscheinen der meinigen (Anglia, N. F. XIII 129/208) wohl zur hälfte beendigt war; der vollständigkeit halber füge ich hinzu, dass meine arbeit fertig war, lange bevor Neuendorff daran dachte die seine zu beginnen, und dass er, als er sie anfing, höchst wahrscheinlich von dem vorhandensein der meinigen und davon wusste, dass ich die hauptsächlichsten quellen des Vicar of Wakefield gefunden hatte. Vielleicht verdient es auch erwähnt zu werden, dass der erste teil meiner arbeit (bis seite 157), der ja so gut wie alle quellen enthält, Neuendorff bereits zwei bis drei monate vor dem erscheinen des ganzen in der Anglia zugänglich war, d. h. zwei bis drei monate vor dem zeitpunkte, wo seine arbeit etwa zur hälfte beendigt war.

Der gegenstand der untersuchung ist bei N. im wesentlichen derselbe wie in meinem aufsatze, nur rückt er übernommene motive und charaktere vielfach über die wirklichen quellen hinaus in einen weiteren historischen zusarnmenhang und erörtert auch einige fragen, die mir fern lagen, so die abfassungszeit des romans, den arrest, zwei angebliche hauptquellen, zugrunde liegende lebensanschauungen und die eingeschobenen gedichte. Die wichtigsten abschnitte, die von den quellen des $\mathrm{V}$. of $\mathrm{W}$. und der art ihrer verwertung handeln, bieten eine reihe dankenswerter ergänzungen zu meiner arbeit. Immerhin bleiben mir einige bemerkungen zu machen.

') Bernhard Neuendorff, Entstehungsgeschichte von Goldsmiths Vicar of Wakefield. Berlin 1903. 
Ich habe längst gewusst, dass ich im ersten findereifer Goldsmiths selbständigkeit zu wenig anerkannt habe. Der gefahr, in diesen fehler zu verfallen, war natürlich nur der ausgesetzt, dem sich zum ersten male die ganze fülle der entlehnungen des dichters aufdrängte, nicht der, der schon die ergebnisse eines andern prüfen konnte. Dafür ist das erste erkennen und aussprechen des neuen aber auch das wesentliche, an einer einmal vorhandenen arbeit im einzelnen mancherlei mängel zu entdecken, das gelingt wohl ausnahmslos jedem, der sich mit demselben thema gründlich befasst. Auch ich habe, selbst nach Neuendorffs dissertation, noch einiges neue gefunden. Es scheint mir darum nicht ganz berechtigt, dass $\mathrm{N}$. die wahrnehmung meines klar zu tage liegenden fehlers für etwas so bedeutsames ansieht, dass er glaubt, nur „einzelbeobachtungen" und „einzelergebnisse" in meiner arbeit anerkennen zu können, und dass er das verhältnis der beiden arbeiten so fasst, als wären zwei verschiedene wege eingeschlagen worden. In wirklichkeit ist es ganz offenbar, dass er auf der meinigen ein wenig weiter gebaut hat und thatsache, dass einerseits alle meine wichtigen ergebnisse in der hauptsache bestehen bleiben, und dass er anderseits nur an einer stelle wesentlich über sie hinausgekommen ist. $N$. hat mich öfter citiert, aber mich nicht, wie er ausdrücklich sagt, bei jeder kleinigkeit als seine quelle angeführt: diese kleinigkeiten füllen zusammen manche seite.

N. weist (s. 44 ff.) mit recht darauf hin, dass Primrose doch bedeutend höher steht als Adams, nur er hat jene „heitere nachgiebigkeit und lächelnde duldung eigener und fremder fehler" (Goethe), nur in ihm sind die christlichen forderungen der erhebung über das irdische und der feindesliebe stark genug, sich auch praktisch zu bethätigen. Was die vorbilder für seinen charakter angeht, so hat N. unbeachtet gelassen, dass Primrose zweifellos auch, wie ich gezeigt hatte, durch die gestalt des pfarrers Harrison in der Amelia beeinflusst ist. Nachdrücklich ist dieser gedanke aufgenommen worden in einer anderen berliner dissertation, ${ }^{1}$ ) deren verfasser

1) Heinrich Schacht, der gute pfarrer in der englischen literatur bis zu Goldsmiths Vicar of Wakefield. Berlin 1904.

Anglia. N. F. XV. 
freilich darin zu weit geht, dass er Harrison als alleiniges vorbild annimmt, während es sich nur um eine zwischenstufe auf dem wege von Adams zu Primrose handelt. Es kommt jedoch noch eine dritte quelle in betracht, die N. und ich übersehen hatten, weil wir es hier nicht mit einem geistlichen zu thun haben. Ich meine den Squire Allworthy im Tom Jones (zwar ist diese figur auch das vorbild für Burchell, aber doch nur in seinem verhältnis zu Thornhill im letzten teile des romans). Mit Allworthy hat Fielding seinen Adams wieder aufgenommen, aber fast ganz ohne lächerliche seiten und überhaupt bedeutend gehoben.

Zunächst etwas äusserliches. Allworthys haus steht am abhang eines hïgels, geschützt von einem wäldchen, in der nähe ist eine wiese, ein bach fliesst vorbei - alles wie bei Primrose. Allworthy als gutsherr nimmt eine ähnliche stellung ein wie unser pfarrer, er ist der vater der gemeinde. Ein geistlicher hat denn auch neben ihm nicht platz, er tritt fast durchweg an dessen stelle. Eine tief innerliche frömmigkeit zeichnet ihn aus, und all sein thun steht mit seinen lehren im schönsten einklang. Wie Primrose benutzt er jede gelegenheit zu wohlgemeinter ermahnung, und diese moralischen belehrungen werden oft etwas lang, einmal wird direkt der ausdruck sermon gebraucht (buch I, kap. 2). Vergleicht man seine ansichten mit denen von Adams, so wird der gewaltige unterschied klar. Adams stellt forderungen auf, die er selbst nicht hält und die daher komisch wirken, Allworthy nimmt das leben wie es ist, seine ansichten sind die eines reifen mannes, der von hoher warte aus verständnisvoll und leidenschaftslos die dinge betrachtet. Er ist von wahrer herzensgüte, dabei ebenso arglos und leichtgläubig wie der vikar. Sein gastfreundliches haus steht jedem verkannten verdienste offen, und nur unglïck ist nötig, um sein mitleid zu erwecken und hilfe zu veranlassen. Kein ängstliches erwägen, er könne wohl einmal unwürdige bedenken, vermag seiner wohlthätigkeit schranken zu setzen. Am wenigsten rührt ihn sein eigenes leid, voll seelenruhe sieht er dem tode entgegen und tröstet seine umgebung. All diese züge stimmen ja auch zu Primrose. Das bezeichnendste aber ist, dass Allworthy auch jene gütige duldung fremder vergehen zeigt. Als er von dem fehltritt der Jenny Jones erfährt, ist er weit entfernt, in den 
allgemeinen gehässigen tadel einzustimmen. Er hält seine pflicht als richter nicht damit für erledigt, dass er die schuldigen bestraft, er sucht sie zu bessern und erfüllt so in seinem kreise die forderung, die Primrose im gefängnis aufstellt (Tauchnitz Edition XXVII, 138 ff.). Er empfängt daher das junge mädchen mit ernster freundlichkeit, verlangt vor allem reue und entwirft sogleich einen plan zu ihrer rettung. Den verführer dagegen beabsichtigt er nachdrücklich zur verantwortung zu ziehen und fragt nach seinem namen. Das mädchen erklärt, schweigen gelobt zu haben, und so gross ist des guten mannes achtung vor dem eid als etwas heiligem, dass er von seinem begehren absteht und keinen bruch des schwures verlangt.

Aehnlich mild und gütig nimmt Primrose die von der mutter so hart verurteilte Olivia auf, die denselben fehltritt begangen hat wie. Jenny Jones. Auch ihm liegt es zuerst daran, dass sie reue zeigt, auch er will dann den namen nicht des verführers, denn den kennt er, sondern des falschen priesters wissen, um ihn bestrafen $\mathrm{zu}$ lassen. Auch Olivia aber hat geschworen ihn zu verschweigen, und der pfarrer dringt nicht länger in sie, denn, meint er, ein eid dürfe allerdings unter keinen umständen gebrochen werden. Die beeinflussung ist wohl deutlich.

Diese ruhige, wohlwollende denkweise zeigt Allworthy noch öfter, so bei kleinen unarten Toms, wo andere verurteilen und strafen, er aber versteht und verzeiht. Der thorheit gegenüber liat er nur ein lächeln (XVII 3):

"Allworthy resented this reflection only with a smile; nor could he, if he would have endeavoured it, have conveyed into that smile any mixture of malice or contempt. His smiles at folly were indeed such as we may suppose the angels bestow on the absurdities of mankind."

Hier haben wir also auch die lächelnde duldung fremder fehler. Immerhin tritt dieser zug nicht oft genug hervor (Allworthy spielt ja ïberhaupt bei weitem keine so bedeutende rolle wie Primrose), um Goldsmith mehr als eine leise anregung gegeben $\mathrm{zu}$ haben. Dass er seinen pfarrer so völlig mit dieser heiteren weltanschauung durchdrungen hat, bleibt sein eigentum.

Jedenfalls sieht man, dass in Allworthy eine weitere vor- 
stufe für den vikar vorhanden ist. Ich erkläre diesen charakter demnach so: das hauptsächlichste vorbild ist Adams, der aber nach dem muster von Harrison und Allworthy zu grösserer würde und einer gefestigten heiteren weltanschauung emporgehoben ist. Den zug der gutmütigen selbstironie mag der dichter aus seinem eigenen charakter übertragen haben. Gerade die thatsache, dass drei vorbilder vorhanden sind, die dennoch den charakter Primroses nicht ganz erschöpfen, zeigt klar, dass Goldsmith an der darstellung dieser so einheitlichen figur ein bedeutendes verdienst bleibt. Vor allem ist in der figur Primroses die idee des ganzen durchaus selbständig und gelungen durchgeführt.

Noch eine äussere übereinstimmung ist $\mathrm{zu}$ finden. Wie Primrose einen sohn hat, Georg, so Allworthy einen pflegesohn, Tom. Der pfarrer Primrose verkehrt mit einem benachbarten pfarrer Wilmot, hier lernt Georg seine Arabella kennen. So verkehrt der Squire Allworthy mit dem Squire Western, seinem nachbarn, und hier lernt Tom seine Sophia kennen. Das verhältnis zwischen Allworthy und Western und zwischen Primrose und Wilmot kann man sich etwa als das gleiche denken. Man verkehrt freundnachbarlich mit einander, aber wirklich herzliche beziehungen sind unmöglich wegen der gar zu weltlichen anschauungen des nachbars. Die liebe der jungen leute muss bei der armut Toms und Georgs unglücklich bleiben.

N. meint ( 52 ff.), wie Primrose weit über Adams gehoben sei, so auch Deborah, die pfarrerin, über frau Adams. Ich selbst hatte gesagt, dass die ansichten und bestrebungen Deborahs nur um eine nüance höher seien als die der frau Adams und das wegen ihrer besseren pekuniären stellung. Weiter zu gehen halte ich nicht für richtig. $\mathrm{N}$. gelangt freilich zu einem scheinbaren beweise seiner behauptung, indem er in seiner charakteristik die gröbsten züge weglässt oder sie mit einiger gewalt in günstiges licht zu rücken sucht. So kann nach ihm "gar keine rede" davon sein, dass sich Deborahs härte gegen Burchell aus ihrem übergrossen familiensinn erkläre, und es ist „unmöglich“, dass dieses verhalten zu dem der frau Adams gegen Fanny in parallele gestellt werde. Ihre härte sei vielmehr "durchaus" am platze, da Burchell der familie als verleumder und heuchler erscheine. Diese 
energischen behauptungen sind deshalb so überraschend, weil ein blick in den roman genügt, um zu zeigen, dass Deborah schon hart gegen Burchell ist, ehe er der familie als verleumder und heuchler erscheint (das ist erst der fall, nachdem man seinen brief gefunden hat), zu einer zeit, wo er ihnen vielmehr nur der lebensretter Sophias ist und man höchstens sein unhöfliches verhalten gegen die beiden damen zu tadeln hat. Da schon wirft sie ihm seine schlecht verbrachte jugend vor und weist ihm die thür (XII. und XIII.). Ja noch mehr: sie thut es nicht nur schon hier, sondern sogar allein hier. Denn nachdem man seine ganze schlechtigkeit entdeckt hat, kommt sie gar nicht mehr dazu, ihren zorn an ihm auszulassen, sie hat erst ein paar mässige und gut parierte scherze machen können, als sie von ihrem manne abgelöst wird. Primrose ist es daher, der Burchell, sobald dieser als heuchler dasteht, mit durchaus berechtigter härte behandelt. N. giebt also die thatsache nicht ganz zutreffend; dabei stellt sich seine irrtümliche behauptung als eine ausdrückliche richtigstellung dar.

Wenn frau Adams manches grobe hat, so Deborah nicht minder. Auf die nachricht von Olivias flucht (XVII 80) ergeht sie sich gegen die verführte wiederholt in ausdrücken, die man nicht anders als roh nennen kann. Auch als Moses sich hat betrügen lassen (XII 53), stehen ihr eine ganze reihe von recht kräftigen verwünschungen und schimpfworten zur verfügung. Ein höherer zug ist es allerdings, wenn sie, wie es im ersten kapitel heisst, darauf besteht, ihre angeblichen armen verwandten, unter denen sich krüppel und lahme befinden, mit an dem familientische $\mathrm{zu}$ bewirten. Aber dieser zug, der eine ausserordentlich hohe und im schönsten sinne christliche gesinnung voraussetzt (verachtung aller äusserlichkeit und der meinung der welt, wahre erkenntnis dessen, was dem christen auf erden frommt), dieser zug wird durch ihr späteres verhalten nicht bestätigt, er passt schlecht $\mathrm{zu}$ ihrer eitelkeit und ihrem streben nach vornehmen bekanntschaften. Es wird sich im verlaufe meiner darstellung öfter zeigen, dass die direkte charakteristik, die Goldsmith von einer person giebt, nicht mit dem charakter übereinstimmt, der sich aus der handlung ergiebt; hier haben wir wohl auch ein beispiel dafür. Der zug ist um so unwahrscheinlicher, als Deborah diese gastfreundlichkeit fast gegen den willen ihres mannes 
auszuüben scheint, umgekehrt wäre es gewiss treffender. Dass im übrigen freigebigkeit $\mathrm{zu}$ ihrem charakter stimmt, darüber ist bei ihrer wirklichen gutmütigkeit kein zweifel, so wenig wie bei frau Adams. Diese erreicht nun freilich nicht eine solche höhe, dass sie, während ihre eigene familie nur mit mühe zu leben hat, gern anderen giebt - aber dieser zug scheint mir auch für Deborah zu hoch, während er sehr gut zu Adams und Primrose passt. Weiter wird von unserer pfarrerin allerdings nicht wie von frau Adams gesagt, dass sie immer das letzte wort hat, sie ist nur redselig, doch liegt der unterschied weniger in den frauen als in den männern: Adams versteht es eben nicht, sich respekt zu verschaffen, wohl aber Primrose.

$\mathrm{N}$. bestreitet, dass der gegensatz zwischen pfarrer und pfarrerin hier und dort ganz gleich sei, womit er insofern recht hat, als er ja gezeigt hat, dass Primrose bedeutend über Adams steht. Dann fährt er fort (s. 54): „Vor allem aber und das hat Fischer völlig übersehen - wird dieser gegensatz im laufe des romans kleiner und kleiner; Goldsmith stellt eine entwickelung in Deborahs charakter dar: je mehr unheil die familie trifft, um so mehr erhebt sich Deborah aus ihren kleinlichen anschauungen." Wenn wir den erwähnten schönen zug mit dem charakter der pfarrerin für verträglich halten, wie $\mathrm{N}$. will, so ist schon damit der gedanke der entwickelung widerlegt: einer der höchsten züge findet sich gleich $\mathbf{z u}$ anfang, die kleinlichen anschauungen offenbaren sich erst später. Ueberblicken wir aber einmal im zusammenhange Deborahs verhalten, seit das erste unglück hereinbricht.

Als Olivia entführt worden ist, tröstet sie ihren mann mit herzlichen worten, wie es ihrem charakter entspricht, aber gegen das mädchen wendet sie sich mit erbarmungsloser härte. Später, bei Olivias rückkehr, hat sie noch immer nur bitteren hohn für die unglückliche, trotzdem ihr stolz tief gedemütigt ist durch das grosse elend, in das der brand des hauses die familie gestürzt hat. Es dauert noch einige zeit, ehe ihre natürliche herzensgüte den sieg davon trägt. Als dann Thornhill dem pfarrer zumutet, seiner vermählung mit Arabella Wilmot ausdrücklich zuzustimmen, da will sie ihn bewegen, den unrechten aber klügeren weg zu gehen - auch jetzt noch aus ihrem alten charakter heraus. Primrose beabsichtigt im 
gefängnis seine leidensgenossen $\mathrm{zu}$ bessern: Deborah ist dagegen, sie hat für ein solch ideales thun ihres mannes kein verständnis. So ist sie auch einverstanden mit dem plane, Olivia für tot auszugeben, um durch Primroses nachgiebigkeit Thornhills zorn zu besänftigen. Als Sophia geraubt ist, tröstet sie ihren mann so gut sie kann, ihre liebe zu ihm, aber doch auch ihr weibliches anlehnungsbedürfnis ist so stark, dass sie kinder und alles verlieren will, wenn er nur ihr erhalten bleibt. Es scheint mir unberechtigt, dass N. diese stelle als einen beweis für die vollendete entwickelung anführt; man beachte: Deborah sagt: they may take away my children, and all the world, if they leave me but you (XXVIII 146); Primrose dagegen denkt im grössten elend stets an alle seine kinder (147).

Schon vorher hat sie, weit entfernt von der christlichen versöhnlichkeit Primroses, Georg in einem briefe aufgefordert, den verführer Olivias zu bestrafen. Jetzt freut sie sich, dass der brief anscheinend verloren gegangen ist, wahrlich nicht, wie $\mathrm{N}$. will, weil jeder gedanke an rache in ihr unterdrückt ist, sondern weil sie bei ruhiger überlegung mit schrecken einsieht, dass dieser schritt auch Georg ins unglück gestürzt haben würde. Diese zweite und letzte stelle, die N. zum beweise der entwickelung beibringt (But thanks be to him that directs all things, it has miscarried, and I am at rest), scheint für sich wohl seine behauptung zu stützen. Aber man lese sie nur im zusammenhange (XXVIII 147), und man wird überrascht sein zu sehen, wie klar, wie unverkennbar es ist, dass Deborah wie ihr mann allein darüber sich freuen, dass die drohende gefahr von Georg abgewandt ist. Nicht die leiseste andeutung findet sich dafïr, dass sie ihre rachegedanken bereut.

Als sie Burchells walıren stand erfährt, gerät sie in die grösste angst und bittet ihn kläglich um verzeihung. Wer hier den noch immer gleich grossen unterschied zwischen beiden gatten verkennt, der verkennt einen der feinsten züge des dichters. Primrose hat Burchell ebenso ungerecht behandelt wie seine frau und weiss das wie diese seit einiger zeit: ihm fällt sein unreclıt ein, und er bittet um verzeihung, sobald Burchell als retter Sophias erscheint. Um ihn ganz zu versöhnen, bietet er dem armen manne freiwillig seine tochter an, die er ihm früher nicht hatte geben wollen. Deborah 
freut sich natürlich über Sophias befreiung, aber sie denkt noch nicht an die grobheiten, die sie Burchell gesagt hat, er ist ja noch immer der arme teufel, der seine jugend schlecht verbracht hat. Kaum hat sich aber der arme Burchell in den reichen und mächtigen Sir William Thornhill verwandelt, da kommen ihr alle ihre sünden wieder ins gedächtnis, da möchte sie in die erde sinken und hält ihr vergehen für unverzeihlich. Primrose also macht seinen fehler gut, sobald er in dem armen Burchell wahres verdienst findet, Deborah erst, als er sich als reicher und vornehmer mann entpuppt.

Der kleine Dick will seinen alten freund Burchell küssen und klettert an ihm empor: sein vater sieht das mit verständnisvollem lächeln an, die mutter aber will ihn für seine vertraulichkeit gegen den grossen Sir William bestrafen kann Deborahs köstliches plebejertum charakteristischer gezeigt werden? Auf Thornhills freche ableugnung seiner verbrechen gewinnt ihr groll durch ihre liebe zur familie die herrschaft über sie, sie nennt ihn ein ungeheuer und zeigt so, dass sie durchaus nicht so versöhnlich denkt, wie N. meint. Und gewiss wird hier niemand versöhnlichkeit verlangen, sie handelt nur natürlich, nur menschlich. An die fast übermenschliche höhe des pfarrers können wir nur eben bei ihm glauben, bei jedem andern wäre sie unnatürlich. Gerade in dieser schlussscene zeigt sie noch einmal ihren ganzen charakter. Der pfarrer schweigt Thornhill gegenüber, sie ist es, die ihrem herzen luft macht, wie immer nicht mit gründen, sondern mit heftigen worten. Als Arabella aufgeklärt werden soll, übernimmt sie natürlich diese aufgabe und ihre glänzende beredsamkeit erscheint zum letzten male in hellem lichte. Ganz zum schluss verrät sich wieder ihre harmlose eitelkeit, es kränkt sie, dass sie nicht an der spitze der tafel sitzen und das fleisch vorschneiden kann - sie bleibt also im grossen wie im kleinen stets ihrem charakter in der glücklichsten weise treu. Von einer entwickelung ist keine rede.

Mir scheint, dass $\mathrm{N}$. durch diese idee der entwickelung verhindert worden ist, Goldsmiths absicht ganz zu erkennen. Goldsmith wollte uns, und zwar von seinem wohlwollenden standpunkte aus, in einer typischen vertreterin jene grosse klasse von frauen zeichnen, die gänzlich im mütterlichen und häuslichen aufgehen. Es sind die frauen, die die wirtschaft 
aus dem grunde verstehen, ihren mann trefflich pflegen und die kinder von herzen lieben, die ihre töchter nur zu dem einen höchsten ziele erziehen, sie möglichst bald und gut verheiraten zu können und keine geistigen interessen haben, kurz die frauen, die man mit den worten beschränkt und gut ziemlich erschöpfend charakterisiert. - Im übrigen ist es klar, dass Goldsmith genug selbständiges verdienst an dieser gestalt bleibt. Denn die quelle bestimmt ja nur ziemlich genau ihren charakter, ihr handeln im einzelnen ist ganz unseres dichters eigentum. - N.'s vermutung, dass Goldsmith in Moses ein bild seiner selbst gegeben hat (s. 58), scheint mir richtig, aber es bleibt gewiss, dass Adams vielfach das litterarische vorbild ist.

Was Georg angeht, so wiederholt N. (s. 55) in der hauptsache, was ich gesagt hatte, doch meint er, Georg zeige mehr sittlichen ernst und halt als Tom Jones, besonders im angesicht des todes. Ich kann ihm darin nicht beistimmen, Tom zeigt gerade dem tode gegenüber ganz dieselben eigenschaften wie Georg. Ueberhaupt ist Georg Goldsmith nicht recht geglïckt. Ich gehe im tadel dieser figur nicht so weit wie Craik, aber es bleibt wunderlich und unvereinbar mit seinem charakter, dass er während seiner dreijährigen abwesenheit gar nichts von sich hören lässt, obwohl er sich lange in der nähe aufhält, dass er so ganz gleichgiltig gegen Arabella erscheint und mancherlei anderes. N. liest, um seine behauptung zu stiitzen, aus Georgs briefe (XXVIII 147;8) heraus, dass ihn seine vergebliche liebe "wirklich unglücklich" mache (nachdem er sich jahrelang nicht um seine frühere braut gekümmert und sie nach kurzem zufälligen wiedersehen ohne kummer verlassen hat!), obwohl ausdrücklich das direkte gegenteil gesagt wird (I am perfectly pleased with my situation, and every way happy here), und er schon, wenn auch noch zögernd, an eine andere dame denken kann. Ja, das vollkommene glück, das aus dem briefe spricht, ist der höchste trost für seine unglücklichen angehörigen.

Seine vergebliche liebe erfüllt ihn nach $\mathrm{N}$. auch ,mit gleichgiltigkeit und verachtung gegen das leben, wodurch er in so eigentïmlicher rauheit erscheint". Ich habe mich vergeblich bemüht, irgend welche berechtigung für diese ansicht zu finden, nur für Tom Jones trifft das alles zu. Georg sagt 
im anfange seiner erzählung, dass niemand je 'a better knack at hoping' als er selbst hatte, und als er gleich nach dem verlust seiner verlobten das vaterhaus verlassen muss, da ist er 'cheerful as the birds that carolled by the road'. Am ende seiner reise ist er freilich sehr gedrückt, aber nur wegen des beständigen missgeschicks, das ihn verfolgt, durchaus nicht wegen seiner liebe. Er verlässt dann seine geliebte und zwar in der gehobensten stimmung (XXI 109). Ebenso wenig verrät sein brief gleichgiltigkeit gegen das leben, wir erfahren daraus ja gerade, dass er glücklich ist und in vergnügungen förmlich schwimmt. Am schluss zeigt er wahre todesverachtung, da er glaubt, dem tode rettungslos verfallen zu sein und es seinem persönlichen mute entspricht, dem unvermeidlichen entschlossen ins auge zu sehen. Ein zusammenhang zwischen dieser todesverachtung und seiner liebe ist nicht vorhanden. Kurz, sein unglück in der liebe erfüllt Georg durchaus nicht mit gleichgiltigkeit und verachtung gegen das leben, es vermag vielmehr seine ausserordentliche lebensfreudigkeit nicht im geringsten über die ersten paar tage hinaus zu dämpfen. Endlich ist es auch nicht ganz richtig zu sagen, Tom Jones sei die reine natur, ein spielball seiner leidenschaften; seine wenigen verfehlungen sind gut begründet. Vor allem aber wird er durch die ereignisse erzogen, bis er seiner Sophia würdig ist.

Für die gegenüberstellung von Olivia und Sophia im ersten kapitel ist, wie N. (s. 56 ff.) wahrscheinlich macht, eine schilderung im Tatler nr. 4 vorbildlich gewesen. N. übersieht aber, dass dieser gegensatz zwischen beiden mädchen nur in dieser direkten charakteristik so scharf hervortritt, dass es sich hier also nur um ein vorbild für die kurze stelle des ersten kapitels handelt. Olivia ist noch am einheitlichsten, aber auch ihr anfangs festgelegter charakter wird später nicht ganz innegehalten. Sie wird direkt eine kokette genannt, und doch zeigt ihr verhalten gegen Thornhill, dass sie höher steht. Denn eben die kokette bevorzugung des einen liebhabers vor dem andern wird ihr durchaus nicht leicht, sie büsst jedesmal dafür mit den bittersten qualen. Nach dem unglück ist sie fast ganz Klarissa, nur dass sie sich auch schuldig weiss und in der liebe getäuscht ist. Man kann also wohl sagen, dass zunächst Klarissa vorschwebte, dass Olivia aber, und zwar z. t. 
unter dem einfluss von Pamela und Adams tochter vielfach leichter erscheint.

Ich hatte darauf aufmerksam gemacht, dass es in keiner weise für Sophia passt, dass sie so putz- und eroberungssüchtig dargestellt wird (derart unnatürlich erscheint sie immer Thornhill gegenüber, sobald Burchell irgendwie in frage kommt, ist sie durchaus verständig und gut). N. giebt das zu und findet auf der nächsten seite Goldsmiths verdienst an beiden mädchen darin, dass er sie gegenüber Richardsonschen „tugendidealen" und "schwindsüchtigen idealgestalten" durch die ausstattung mit diesen schwächen zu wirklichen und lebenswahren menschen gemacht hat. Selbst für Olivia scheint es mir eine wunderliche auffassung, dass sie erst durch ihre koketterie und ihr verzweifeltes streben nach einer guten partie lebenswahr geworden sei. Im übrigen stimmt N. mir darin bei, dass Miss Byron aus dem Grandison das vorbild für Sophia ist.

Ueber Burchell sagt N. (s. 61;62) im wesentlichen dasselbe wie ich. Er zählt die charakteristischen züge auf, die Burchell mit Grandison gemeinsam hat, und die ich sämtlich schon dargelegt hatte: am schlusse nennt er mich ausdrücklich für einen ganz nebensächlichen zug als seine quelle. N. zeigt darauf weiter die übereinstimmungen mit Allworthy und spricht ïber die verschmelzung beider charaktere. Dann fährt er fort: „Da nun Burchell am schluss genau dieselben tugenden zeigt, wie Allworthy (grossmut, milde, klugheit, ja weisheit, gerechtigkeit, dabei grosse vornehmheit des wesens und dadurch überlegenheit über die anderen), so hat hier, wenn anch Grandison die gleichen hat, sicherlich Allworthy vorgeschwebt, da er ja auch dessen stelle einnimmt, und so ist es sicher falsch, wenn Fischer von Grandison als der einzigen quelle für Burchells charakter spricht."

Aus dieser darstellung kann niemand das wirkliche verhältnis von N.'s ansicht zur meinigen erkennen. Auf seite 150 habe ich im zusammenhange mit der entlehnung aus Sir Charles Grandison gezeigt, wie Burchell genau Grandison nachgebildet ist; auf seite 158, gelegentlich der entlehnung aus Tom Jones, dass Burchell das getreue abbild Allworthys ist, mit einer anmerkung, dass ich über die verschmelzung von Grandison und Allworthy zu Burchell später sprechen würde; das ge- 
schieht dann ausführlich seite 170/4. Man ersieht daraus einerseits, dass ich mit aller entschiedenheit und klarheit genau das gegenteil von dem gesagt habe, was N. mir unterschiebt und anderseits, dass das, was er in scharfer polemik gegen mich als sein eigentum hinstellt, das aufzeigen der verschmelzung beider charaktere, schon von mir nachdrücklich dargelegt worden ist und $\mathrm{zu}$ den hauptergebnissen meiner arbeit gehört. Eine belegstelle für meine angebliche falsche ansicht hat N. denn auch, seiner gewohnheit entgegen, nicht angeführt.

Aber der abschnitt über Burchell enthält auch etwas neues, eine dritte quelle. Im dritten kapitel erzählt Burchell seine entwickelungsgeschichte. N. meint nun, hier habe Goldsmith seine eigene person in die verhältnisse eines hochgestellten und reichen mannes gesetzt und verweist auf eine übereinstimmung im Citizen of the World (brief XXVII). Diese vermutung scheint mir nicht zutreffend. Zunächst ist festzuhalten, dass es für den Burchell, der im roman selbst handelnd auftritt, nur die von mir erwähnten beiden quellen giebt, von dem manne, der er in seiner erzählung ist, findet sich später keine spur mehr. Es zeigt sich eben aufs neue, dass eine direkte charakteristik mit der handlung nicht im einklang steht. Es fragt sich also nur, ob für diese stelle des dritten kapitels ein vorbild vorhanden ist. Das existiert allerdings. Grandison erzählt einmal (III 59 ff.) ähnlich wie Burchell von seiner vorgeschichte. Sein vater hatte einen fehler, unter dem er selbst am meisten litt, er verstand es nicht, das seinige zusammenzuhalten. Er hatte 'an extravagant turn, magnificence was his taste', auch seine 'munificence' wird erwähnt. Dadurch hat er sich so vollkommen ruiniert, dass Lord W., als der junge Sir Charles nach dem tode seines vaters zu ihm kommt, iiberzeugt ist, er wolle ihn um geld bitten und sich schon zu einer abschlägigen antwort rüstet. Sir Charles selbst hat ja ähnliche neigungen, nur weniger zur verschwendung im allgemeinen als zur freigebigkeit. Das schlechte beispiel seines vaters aber hat ihn gewarnt, er hat seine vermögensumstände geordnet und ist heute wieder wohlhabend geworden. Man erkennt ohne zweifel, dass hier das vorbild für Burchells erzählung zu suchen ist. Burchell ist zunächst Grandisons vater, dessen verschwendungssucht gänzlich zu einer krankhaften freigebigkeit und wohlthätigkeit geworden ist. Er kommt 
dann zur besinnung und wird zum jungen Grandison selbst, der vernünftiges wohlthun anstelle der sinnlosen schenkerei setzt und wieder $\mathrm{zu}$ geordneten verhältnissen gelangt. (Da Burchell vater und sohn in sich vereinigt, so findet sich in der erzählung auch nicht die leiseste erwähnung seines vaters oder einer erziehung.) Wir sehen wieder, dass die benutzung zu vieler quellen eine unebenheit herbeigeführt hat: was als entwickelung vom vater zum sohne recht gut möglich ist, wird höchst unwahrscheinlich, sobald es sich in dem einen Burchell abspielt, der uns schliesslich als 30jähriger liebhaber entgegentritt. Die erzählung ist sonst aber recht hübsch und auch selbständig ausgeführt.

Die bisher erwähnten quellen bestimmen Burchells charakter und sein thun als Sir William Thornhill, sein auftreten als Burchell im ersten teile war damit nicht gegeben. Die darstellung seines wanderlebens ist zum guten teile des dichters eigentum, ein einheitliches vorbild dafür scheint es nicht zu geben. Ich hatte gesagt, dass wohl Sir Lancelot Greaves gewirkt hat. Von Adams, der ja auch soviel umherwandert, stammen zwei kleine, aber bezeichnende züge. Oefter wird in scherzhafter weise von Adams' schnellfüssigkeit berichtet, die postkutsche kann ihn nicht einholen: dieselbe eigentümlichkeit wird ebenso launig von Burchell angeführt (III 14). Beide haben einen derben stock bei sich, den sie gewandt $\mathrm{zu}$ handhaben wissen. Während aber dieses motiv bei Fielding zu nichts besonderem führt, hat Goldsmith es recht geschickt derart verwandt, dass diese schnellfüssigkeit Burchell in stand setzt, die kutsche, in der Sophia entführt wird, einzuholen und schliesslich direkt die entdeckung des schuldigen veranlasst (XXX 157, 161). Der andere zug ist, dass Burchell wie Adams ärztliche kenntnisse besitzt.

Endlich stammt einiges aus 'Tom Jones. Das verhältnis zwischen Georg und Arabella tritt besonders im ersten teile stark zurück gegenüber der geschichte 'Toms und Sophias. So konnte Goldsmith für Burchell einen zug von Tom übernelımen während der zeit, wo Georg nicht auftritt. Eine gewisse ähnlichkeit besteht ja zwischen dem armen Burchell und seiner Sophia und Tom Jones und Sophia Western. Tom rettet Sophia das leben (IV 13), sie dankt ihm durch einen blick, der ihre liebe verrät, und ihre neigung zu ihm gewinnt 
an stärke. So rettet Burchell Sophia (III 16), auch sie dankt inm mehr durch blicke als durch worte und beginnt ihren retter zu lieben. Die eltern Sophias behandeln Burchell zwar freundlich, aber sie denken nicht daran, seine armut um seiner guten that willen $\mathrm{zu}$ vergessen, selbst Primrose steht seiner liebe zu Sophia direkt feindlich gegenüber. Auch dieser etwas befremaliche zug hat wohl in der quelle seinen ursprung, denn so gütig und herzlich Western gegen Tom ist, so beeinflusst inn weder seine freundschaft noch die dankbarkeit, die er empfinden sollte, im geringsten, sobald es sich darum handelt, ihm seine tochter zu geben.

Das verdienst Goldsmiths an der gestalt Burchells findet $\mathrm{N}$. darin, dass Goldsmith uns zeige, wie sein charakter entstehen konnte. Richardson stelle Grandison von vornherein als engel hin, Goldsmith habe Burchells jetziges wesen als begründet durch seine lebenserfahrungen hingestellt und ihm dadurch grosse lebenswahrheit gegeben. Das sei auch der grund, weshalb Burchell nicht lächerlich wirke wie Grandison.

Sehen wir, ob das richtig ist. Ich bemerke zunächst, dass Goldsmith einen wichtigen zug, den Burchell von Grandison überkommen hat, unerklärt lässt, seine duellgegnerschaft. Dass ein junger mann von der gesellschaftlichen stellung Grandisons und Burchells einen solchen standpunkt einnimmt, ist sicherlich auffällig. Richardson hat es durchaus befriedigend motiviert. Grandison ist schon früh von seiner mutter auf die verwerflichkeit des zweikampfes hingewiesen worden, und diese haltung einer frau ist nur natürlich. Dann aber ist Grandisons vater einst in einem duell schwer verwundet worden, und seine mutter ist an den folgen des schreckes gestorben. Im V. of W. ist keine erklärung gegeben, sie wäre aber um so erwünschter, als Burchells duellgegnerschaft später von grosser bedeutung wird. Man erkennt schon hieraus, dass die behauptung, Richardson stelle Grandison von vornherein als engel hin, nicht so ganz richtig ist. Erwägt man weiter, dass Grandisons vater nicht nur in dieser hinsicht, sondern auch in bezug auf seine verschwendungssucht und seinen lockeren lebenswandel seinem sohne ein abschreckendes beispiel bot und dass diesen anderseits eine vortreffliche mutter erzog, die unter den ausschweifungen ihres mannes schwer zu leiden hatte, so ergiebt sich, dass Richardson keineswegs so ungeschickt und un- 
künstlerisch verfuhr, wie N. glaubt. Ich verteidige im übrigen einen charakter wie Grandison nicht, ich will nur feststellen, dass gerade Richardson Grandisons „jetziges wesen als begründet durch seine lebenserfahrungen hinstellt".

Beide dichter also haben uns die entwickelung ihrer helden nicht wirklich vorgeführt, sondern lassen sie erzählen. Burchells erzählung an sich ist ganz vortrefflich, viel wirkungsvoller als die Grandisons, nur erfüllt sie leider nicht den zweck, für den sie bestimmt war. Ich weise ferner darauf hin, dass $\mathrm{N}$. erst von der "grossen lebenswahrheit" spricht, die Burchell eben durch die gegebene entwickelung erhalten habe und wenige zeilen darauf zugiebt, dass die verbindung der drei charaktere „äusserst unglücklich" sei, dass die entwickelung nicht zu dem späteren Burchell passt.

Endlich bleibe ich dabei, dass die verschiedene wirkung beider figuren, Burchells und seines vorbildes Grandison, sich daraus erklärt, dass uns des letzteren vorzüge unaufhörlich in der aufdringlichsten weise vor augen geführt werden, dass die hervorhebung dieser vorzüge zweck der dichtung und eine eigentliche handlung nicht vorhanden ist, wogegen Burchell ohne eine solche tendenz in eine bewegte handlung mitten hinein gestellt wird.

$\mathrm{Zu}$ 'Thornhills charakter hat N. (63 ff.) nichts neues gebracht. Aber während ich ihn auf Lovelace und Blifil zurückführe, erklärt ihn N. aus einer verschmelzung von Lovelace und dem Lord B. in der Pamela. Ich hatte auf die kleinen übereinstimmungen mit der Pamela hingewiesen, N. hat das wiederholt und dann den Lord B. mit zur erklärung Thornhills herangezogen.

Davon kann keine rede sein. In der handlung nimmt Thornhill nur an zwei punkten die stelle Lord B.'s ein, später ist er fast immer Lovelace und Blifil. N. kann nur einen einzigen zug anführen, der den einfluss Lord B.'s beweisen soll: die unverschämtheit, mit der er Pamela entgegentritt, ähnelt der, mit der Thornhill sich den pfarrerstöchtern gegenüber benimmt. Aber dieser zug, auf den ich schon hingewiesen hatte, stimmt wie noch mancher andere vollkommen auch zu dem charakter Lovelaces, wie überhaupt zu dem fast jedes wüstlings, kann also gar nichts beweisen. N.'s annahme ist etwa ebenso berechtigt, wie die einer vierten quelle in der 
person des Sir Hargrave Polleæfen, denn Thornhill handelt ja auch einmal wie dieser (entführung Sophias) und auch dieser hat züge, die zu Thornhill passen. Bei N. aber ergiebt sich die wunderbare thatsache, dass er zwar die übereinstimmungen der umfänglichen handlung zwischen Thornhill und Georg, Arabella, Burchell mit der zwischen Blifil und Tom Jones, Sophia Western, Allworthy zugesteht, also zugesteht, dass Thornhill in vielen punkten genau so handelt, wie Blifil und doch die übereinstimmung der charaktere nicht zugeben will. Nur ganz am schluss erwähnt er einen von Blifil stammenden zug im charakter Thornhills, auf den ich aufmerksam gemacht hatte: sein widerliches flehen, als seine sache verloren ist. Er lässt unbeachtet, dass ausserdem dorther stammen seine geldgier (nach Arabellas vermögen; bei Lovelace findet sich keine spur davon); sein gänzlicher mangel an wahrer liebesempfindung (Lovelace ist von wirklicher leidenschaftlichkeit); sein heimtückisches verhalten gegen Georg (Lovelace würde einem nebenbuhler mit der waffe in der hand entgegen getreten sein); die abgefeimte heuchelei, mit der er sich Burchell gegenüber als freund der tugend aufspielt, überhaupt das vorsichtige verhalten zum onkel (Lovelace trotzt offen mit seinen verwandten). Das sind eine ganze reihe charakteristischer züge, die nur von Blifil stammen und nicht $\mathrm{zu}$ Lovelace stimmen. Ich fasse zusammen: Mr. B. handelt nur zweimal wie Thornhill, kein irgendwie beweisender zug Thornhills stammt von ihm. Auf der anderen seite verhält sich Thornhill in der gesamten aus Tom Jones entlehnten handlung wie Blifil, viele charakteristische und beweisende züge sind von diesem auf ihn übergegangen: N.'s behauptung. stützt sich also auf keine einzige entscheidende thatsache und lässt die klarsten beweise ausser acht. Er hat denn auch hier in keiner weise gegen mich polemisiert, obwohl er eine so verschiedene ansicht aufstellt. Die zusammenschmelzung von Lovelace und Blifil zu Thornhill scheint mir ein unanfechtbares faktum. Man verzeihe diese kategorische ausdrucksweise. Ich bin mir bewusst, und habe es in meiner darstellung wohl auch gezeigt, dass ich allein sachliche interessen habe und jeder belehrung zugänglich bin; hier aber handelt es sich um ein so gesichertes ergebnis, dass mir die nachdrücklichste abweisung der entgegenstehenden ansicht nötig scheint. 
Uebrigens ist der bildungsunterschied zwischen Lovelace und Thornhill nicht so bedeutend, wie N. meint. Anfänglich freilich wird Lovelace als wirklich gebildeter mann hingestellt, aber später finden sich zahlreiche stellen, aus denen hervorgeht, dass seine bildung nicht so hervorragend ist. Er ist gut beanlagt und hat mancherlei gelesen, aber wenig gedacht, er ist Klarissa nicht gewachsen.

Ein gemeinsamer zug, den ich übersehen hatte und den auch $\mathrm{N}$. nicht bringt, ist, dass sie beide freidenker sind, aber sich gelegentlich auch fromm stellen, wenn es gilt, ihre zwecke einem mädchen gegenüber zu erreichen. Einen charakterfehler hat Goldsmith selbst hinzugefügt, die feigheit.

Bei der vergleichung von Lovelace und Thornhill kommt N. zu dem ergebnis, dieser sei ein wahrerer charakter, weil er gänzlich ohne gute seiten sei, jener dagegen sei aus zwei typen zusammengeschmolzen, dem blendenden wüstling und dem freundlichen gutsherrn. Ein solcher charakter sei uns unwahrscheinlich. Das ist eine höchst wunderliche ansicht. Lovelace ist eine durchaus einheitliche, lebenswahre figur, nur bei seiner ausgesprochenen vorliebe für Goldsmith konnte $\mathrm{N}$. auf einen solchen gedanken kommen. Lovelace hat, das wird einmal direkt gesagt, eigentlich nur einen fehler, und solche persönlichkeiten, gewinnend, liebenswürdig, ritterlich, im grunde meist gutherzig, aber mit einer grossen schwäche für frauen, denen gegenüber ihr ehrbegriff ein gänzlich anderer ist als männern gegenüber, sind von Molinas Don Juan bis zu Dickens' Steerforth und später unzählige male in mannigfacher variation und höchster lebenswahrheit gezeichnet worden, und ohne mühe liesse sich eine ganze reihe historischer personen mit ähnlichem charakter nennen. Dagegen ist die fülle der laster in Thornhill kaum mehr glaublich. Man vermag sich in Lovelace hineinzudenken und kann ihn verstehen, von Thornhill erfährt man immer nur eine schändlichkeit nach der andern, ohne dass man sich über die dahinterstehende persönlichkeit klar wird. $\mathrm{Fr}$ ist einfach zu einer verkörperung des bösen prinzips, zum typischen bösewicht geworden. Will man nicht den einen dichter auf alle fälle höher stellen, so kann darüber kein zweifel sein, dass Lovelace künstlerisch weit über Thornhill steht.

$\mathrm{Zu} \mathrm{Wilmot}$ und Arabella, seiner tochter, bringt $\mathrm{N}$. Anglia. N. F. XV. 
nichts neues, nur erklärt er ihre unbedeutende rolle aus bewusster absicht Goldsmiths. Meine auffassung ist diese: Goldsmith konnte natürlich die dritte handlung nicht gleichzeitig neben den beiden andern hergehen lassen. Dieses zurücktreten brachte das gewiss nicht erwünschte ergebnis mit sich, dass Arabella und ihr vater sehr wenig charakterisiert wurden. Wilmot selbst hat wenigstens einen ausgeprägten zug bekommen, Arabellas charakter aber bleibt so unklar und verschwommen, dass man von Goldsmiths fähigkeiten sehr gering denken muss, um hier bewusste absicht $\mathrm{zu}$ sehen. Uebrigens hat unser dichter es sonst auch verstanden, mit wenigen zügen treffend zu charakterisieren.

Ueber Jenkinson sagt $\mathrm{N}$. ungefähr dasselbe wie ich (s. 66/67). Dass er nicht ganz gelungen ist, wie ich gezeigt hatte, bestreitet N. nicht; aber, meint er, man werde daran kaum anstoss nehmen, weil Jenkinson eine so nebensächliche figur sei. Einige zeilen zuvor hat er zugegeben, dass Jenkinson wesentlich zur lösung der intrigue beitrage. Das ist gewiss richtig, die lösung könnte ohne ihn gar nicht erfolgen, er ist also durchaus keine nebensächliche figur.

Den rivalen Thornhills, Williams, führt N. nicht wie ich auf den pfarrer Williams in der Pamela zurück, sondern auf den Mr. Solmes in der Klarissa. Zweimal (s. 21 anm., 67/68) betont er, dass sich seine rolle "nicht im geringsten" und "durchaus nicht" mit der des pfarrers Williams vergleichen lasse. Er hat sicherlich darin recht, dass die thatsache der verwendung eines nebenbuhlers nach dem vorbilde der Klarissa erfolgt ist: wie die einführung Solmes' Klarissa zur flucht zwingt, so die des Williams Olivia. Damit aber hört die ähnlichkeit auf: Solmes wird in der ernstesten absicht herangezogen, um Lovelace zu entfernen, Williams dagegen ohne ernste absicht, gerade um Thornhill zur erklärung zu bringen.

Diese wesentliche änderung ist Goldsmiths eigentum. Für die näheren umstände aber ist die Pamela massgebend gewesen. Die eltern Klarissas wünschen Solmes als schwiegersohn aus den materiellsten gründen, und obwohl er ein erbärmlicher, verächtlicher geselle ist, dem gegenüber Lovelace entschieden höher steht. Ganz anders hier. Die eltern Olivias (und Pamelas) haben nichts gegen Williams, weil er ein durchaus ehrlicher, herzensguter mensch ist, der weit über seinem vor- 
nehmen rivalen steht. Klarissa verabscheut Solmes, liebt aber auch Lovelace nicht, während Olivia (wie Pamela) dem Williams wohlgesinnt ist und seinen nebenbuhler liebt. N. meint nun, pfarrer Williams sei äusserst aktiv, unser farmer aber ganz passiv. N. selbst hat bei der aus der Klarissa entnommenen handlung, auf die ich gleich kommen werde, gezeigt, wie Goldsmith diese handlung den veränderten umständen angepasst hat, hier lässt er diesen gesichtspunkt nicht gelten. Pfarrer Williams will ein gefangen gehaltenes mädchen befreien, muss also sehr aktiv sein; hier lebt das mädchen friedlich bei seinen eltern, beide bewerber gehen im hause aus und ein, die verhältnisse sind daher ganz andere. Wenn der farmer der mann ist, im notfalle dieselbe aktivität zu entfalten wie der pfarrer, so kann er das hier nur dadurch zeigen, dass er Thornhill energisch und ohne furcht entgegentritt, und das wird ausdrücklich gesagt (XVII 73). Einen weiteren unterschied (die aufgezählten ähnlichkeiten übersieht er gänzlich) findet N. darin, dass pfarrer Williams noch auf erhörung hoffen könne, da Pamela dem Lord B. abgeneigt sei, während des farmers versuche von anfang an aussichtslos waren. IDiese darstellung entspricht nicht den thatsachen. Pamela ist dem Squire durchaus nicht abgeneigt, im gegenteil liebt sie ihn wirklich. Die lage ist also die gleiche: die sache des pfarrers und des farmers ist aussichtslos, und zwar zum grossen teil deshalb, weil der gegner ein reicher und vornehmer herr ist.

Farmer Williams wird auch nach Olivias rückkehr noch einmal erwähnt (XXIII, 119), er will sich ihr wieder nähern und seine werbung erneuern. Dieser zug stammt aus der Klarissa. Mr. Wyerly hat sich früher um Klarissa beworben, ist aber abgewiesen worden. Nachdem das unglück geschehen, erscheint er gleichwohl aufs neue und wirbt in einfachen, herzlichen worten noch einmal um sie, natürlich ebenso vergeblich wie Williams.

Wir sehen also auch hier, was wir bei Goldsmith so oft beobachtet haben: er nimmt von einer ganzen reihe verschiedener personen passende züge für eine von seinen figuren. Er führt einen nebenbuhler ein nach dem muster des Solmes der Klarissa, der Olivia zur flucht zwingen soll. Den charakter des nebenbuhlers und die weiteren verhältnisse formt er nach dem pfarrer Williams der Pamela, nimmt endlich einen hübschen 
zug von Mr. Wyerly der Klarissa und hat so wirklich auch diese kleine rolle so anziehend und charakteristisch gestaltet, wie es mit wenigen zügen nur möglich war.

Ich komme jetzt zu den drei handlungen, die Goldsmith entlehnt hat. Was zunächst die zwischen Olivia und Thornhill angeht, so hat N. (s. 18 ff.) keine neuen thatsachen gebracht, aber er hat im einzelnen gezeigt, wie Goldsmith seinen besonderen verhältnissen entsprechend geändert hat. Lovelace muss Klarissa erst entführen, Thornhill wendet seine gemeinen mittel vorher an, die entführung bringt ihm die erfüllung seiner wünsche.

Nicht mit allem einzelnen bin ich einverstanden. N. sagt: „Auf sehr geschickte weise benutzt Goldsmith dies eingreifen Burchells, das der vikar missversteht, um ihn auf lange zeit vom hause des vikars zu entfernen, da es sonst schon früher zur lösung hätte kommen müssen." Es scheint mir, dass hier $\mathrm{N}$. in seiner vorliebe für Goldsmith zu weit geht. Das eingreifen Burchells besteht in jenem briefe, durch den, wie ich gezeigt hatte, die handlung eigentlich unmöglich wird, da die entdeckung damit schon erfolgt. Nun dieses mittel, das angewandt wird, um Burchell auf lange zeit vom hause des vikars fernzuhalten, „da es sonst schon früher zur lösung hätte kommen müssen", das aber thatsächlich eben diese lösung herbeiführt - dieses mittel sehr geschickt zu nennen, das ist eine doch $\mathrm{zu}$ wohlwollende beurteilung.

Im weiteren hat $\mathrm{N}$. etwas scheinbar recht hübsches herausgefunden, ich will ihn darum citieren. Thornhill lässt sich nicht zur aussprache treiben und nun (s. 21) „greift Deborah zu einem kräftigeren mittel, das hernach so verhängnisvoll wird; sie führt einen rivalen ein, den rechtschaffenen, stillen und zurückhaltenden farmer Williams. Dieser muss nun verhängnisvoll werden, wie Mr. Solmes für Klarissa. Dazu benutzt Goldsmith die ehrenhaftigkeit des vikars. (Man beachte: die einführung des rivalen war durchaus begründet durch den charakter Deborahs, sie entspricht ihrem vorsorglichen sinn; verhängnisvoll wird dieses mittel durch den charakter des vikars. Wie ungemein geschickt weiss Goldsmith das fremde motiv in den roman hineinzuflechten!)" Und auf der nächsten seite: „Das geschickteste aber ist, dass Goldsmith die ent- 
wickelung seiner geschichte unmittelbar durch die charaktere seiner personen eintreten lässt: nur eine Deborah konnte auf den gedanken kommen, einen rivalen einzuführen, um Thornhill zur aussprache $\mathrm{zu}$ bewegen; nur durch die strenge ehrenhaftigkeit des vikars konnte dieses mittel verhängnisvoll werden."

Die einzige schwierigkeit hierbei ist, dass die sache nicht ganz so liegt, wie N. sie darstellt. „Nur eine Deborah konnte auf den gedanken kommen, einen rivalen einzuführen " woher weiss denn N. das? Im 16. kapitel wird zweimal dieser plan erwähnt, und jedesmal heisst es: it was resolved, keine andeutung findet sich, dass Deborah das mittel vorschlägt. Gewiss mag man sich denken, dass ein solches verhalten recht gut zu ihrem wesen passen würde, aber auf eine vermutung hin darf man doch nicht mit so grosser energie betonen, dass nur sie allein es thun kann. Uebrigens lässt uns der dichter nicht darüber im zweifel, wer auf diesen gedanken gekommen ist; zufällig ist es nicht Deborah, sondern Olivia. Im 17. kapitel heisst es, gerade als über diese angelegenheit gesprochen wird:

"Olivia, my darling", returned I, „every scheme that has been hitherto pursued to compel him to a declaration has been proposed and planned by yourself."

Auch scheint es mir die sachlage nicht zutreffend wiederzugeben, wenn $\mathrm{N}$. die strenge ehrenhaftigkeit des pfarrers, über die es natürlich an sich gar keinen zweifel giebt, in diesem zusammenhange so stark betont. Primrose drängt darauf, dass ein termin für die hochzeit mit Williams festgesetzt wird, und Olivia verpflichtet sich, diesen wirklich zu heiraten, wenn nicht Thornhill sich in der zwischenzeit erklärt. Nun also die strenge ehrenhaftigkeit des pfarrers gewirkt hat, liegt die sache so: wenn Thornhill auch nur einen tag vor dem angesetzten hochzeitstage Olivia einen offiziellen antrag macht, so wird er vorgezogen und Williams getäuscht. Dass das kein streng ehrenhaftes vorgehen ist, leuchtet ein; nachdem ein tag für die hochzeit mit Williams bestimmt war, durfte es kein zurücktreten mehr geben. Wenn Primrose seinem streng ehrenhaften charakter hier treu geblieben wäre, so hätte er, der sonst wie zu erwarten fortune-hunting women verächtlich findet, dies niedrige fortune-hunting überhaupt nicht erlauben dürfen. Niemand ist sich darüber klarer als 
er selbst. Aber auch er hat eben kleine weltliche schwächen und möchte gern einen vornehmen schwiegersohn haben. So lässt er sich, als die ganze familie auf ihn einstürmt, bewegen, dem plane Olivias zuzustimmen, aber doch nur mit halbem herzen. Er wird ein unbehagliches gefühl nicht los und um sein gewissen $\mathrm{zu}$ beschwichtigen, lässt er wenigstens einen termin festsetzen. Als es sicher scheint, dass Thornhill verzichtet und Williams belohnt wird, da wird er wieder herr über seine schwäche und ist von herzen einverstanden mit der bescheideneren partie. Um so schwerer ist dann die tragik, dass ihm die nachricht von Olivias flucht kommt, als er eben jede schlimme folge seiner allzu grossen nachgiebigkeit gegen die wünsche der familie beseitigt glaubt.

N. meint, wenn Thornhill Olivia ganz besitzen wolle, so sei es bei einer tochter Primroses klar, dass das nur, wenigstens ihrer meinung nach, rechtlich geschehen könne. Er nennt daher auch Thornhill Olivias vermeintlichen gatten. Ich hatte darauf hingewiesen, wie wunderlich es ist, dass Olivia die ungiltigkeit der trauung kennt; es handelt sich eben wieder um ein versehen Goldsmiths. Allein es geht doch wirklich nicht an, dass $\mathrm{N}$. auch hier die thatsächlichen verhältnisse nicht nur ignoriert, sondern sie so umändert, wie es besser wäre und also argumentiert auf der grundlage, dass Olivia nach ihrer meinung rechtlich verheiratet ist. Olivia sagt aber ganz klar (XXI 113), sie habe gewusst, dass die zeremonie in keiner weise bindend gewesen sei.

Im übrigen gebe ich gern zu, dass meine bezeichnung der geschichte Olivias als eines guten auszugs aus der Klarissa der selbständigkeit Goldsmiths nicht gerecht wird.

Für die handlung zwischen Sophia und Burchell citiert N. (s. 24) meine darstellung und fügt nichts neues hinzu.

Auch für die handlung zwischen Georg und Arabella führt N. (s. 24 ff.) meine zusammenfassung an und bringt nichts neues. Dafür sagt er: „Fischer hat für diese übernahme nur worte schärfsten tadels. So sagt er: 'Es ist schon undenkbar, dass Georg, dieser gute sohn, während der universitätsjahre nie daheim von seinem busenfreunde erzählt hat'; er rechnet aus, dass Georgs reise zeitlich unmöglich ist - erinnert das alles nicht ein wenig an Gottscheds forderungen, der sich am liebsten mit hervorgezogener uhr in das theater gesetzt hätte?" 
Ich bemerke zunächst, dass ich die übernahme an sich nicht getadelt habe, sondern nur die art, wie Goldsmith diese handlung mit dem ganzen verschmolzen hat. Nun zu dem ersten punkte, den N. anführt. Die möglichkeit, dass Thornhill in der pfarrerfamilie unheil anrichten kann, beruht grösstenteils darauf, dass man ihn nicht recht kennt, man hat ihn ja nur einmal von einem fremden tadelnd nennen hören. Es ist daher notwendig, dass, wie ja auch selbstverständlich, keinerlei frühere verbindung zwischen ihm und der familie bestanden hat. Die späteren ereignisse wären unmöglich, wenn Wakefield der schauplatz geblieben wäre, denn dann wären der patron und sein oheim den Primroses genau bekannt gewesen. Dies ist der innere grund für den äusserlich so schlecht motivierten umzug.

Ich wiederhole: Goldsmith legt mit gutem grunde grossen wert darauf, dass Thornhill und sein onkel der familie unbekannt sind. Da ist es nun interessant zu beobachten, wie der dichter viel später in zu enger nachahmung des Tom Jones dazu gelangt ist, Georg zum vertrautesten freunde Thornhills zu machen; denn hier stellt sich ein offenbarer widerspruch heraus. Georg ist noch daheim, als der neue wohnort und damit der neue patron bekannt ist: wenn er nicht früher von Thornhill erzählt hat, so müsste er es jetzt thun, er hat ihn ja erst vor einigen monaten verlassen. Aber Goldsmith hat die rückwirkende konsequenz dieser bekanntschaft übersehen; wir haben ja öfter ähnliche vergesslichkeiten entdeckt.

$\mathrm{N}$. findet sich mit diesem widerspruche nicht nur so ab, dass er meine erwähnung als lächerlich hinstellt, sondern er erklärt sogar diese frühere bekanntschaft Georgs mit Thornhill für eine sehr gute selbständige motivierung! Das ist nun freilich eine seltsame art litterarischer kritik. Ich meinerseits, der ich nicht die tendenz hatte, Goldsmiths schwächen zu verbergen, sondern nur die, ihn recht $\mathrm{zu}$ verstehen, welchen grund hätte ich haben können, einen so interessanten widerspruch unerwähnt zu lassen? Die verschiedensten litterarhistoriker haben auf unwahrscheinlichkeiten und widersprüche im V. of W. aufmerksam gemacht, auch auf weniger auffallende als den von mir erwähnten. Nach N.'s ironischer ausdrucksweise möchte man meinen, er halte verstösse gegen die wahrscheinlichkeit überhaupt für unerheblich und nicht nennenswert 
aber zwei seiten später findet man mit staunen, dass auch er von „ganz unverständlichen widersprüchen" und mannigfachen unwahrscheinlichkeiten" redet, ja dass er selbst eine unwahrscheinlichkeit anführt, an der ich keinen anstoss genommen hatte, die ich einer erwähnung gar nicht für wert halte. N. thut also prinzipiell dasselbe wie ich und geht durch die anführung einer so unbedeutenden kleinigkeit faktisch weiter als ich. Sein angriff erscheint so in merkwürdigem lichte.

Weiter zeugt es von einer eigenartigen logik, auch nur entfernt die beiden thatsachen mit einander zu vergleichen, dass man einem drama von vornherein eine bestimmte zeitgrenze setzt, und dass man einen chronologischen fehler anmerkt, d. h. mit einander zu vergleichen eine zopfige, missverstandene und längst abgethane regel und ein selbstverständliches und allgemein giltiges gesetz. Ich gestehe, dass es mir trotz $\mathrm{N}$. für das verständnis Goldsmiths recht lehrreich scheint $\mathrm{zu}$ sehen, dass er in seiner sorglosigkeit Georg innerhalb von fünf monaten eine reise von drei jahren machen lässt.

Ganz etwas anderes ist es natürlich, ob man solche versehen scharf tadeln will oder nicht. Was meine meinung darüber ist, habe ich mit aller deutlichkeit ausgesprochen. Ich habe gesagt (s. 174), dass ich es für pedantisch halte, auf ein paar unebenheiten, die sich schliesslich in jeder dichtung finden, grosses gewicht zu legen und den dichter zu verurteilen; ich habe keinen zweifel darüber gelassen, dass mein urteil nur wegen der grossen fïlle dieser versehen hart ausgefallen ist. N. aber hat unter nichtbeachtung meiner klar ausgesprochenen meinung mehrere einzelne von mir getadelte widersprüche aus dem grossen zusammenhange herausgerissen und so den schein einer kleinlichen kritik meinerseits hervorgerufen. Die beurteilung eines solchen verfahrens überlasse ich dem unparteiischen leser.

N. meint dann, die auflösung der verlobung Georgs sei genau motiviert. Goldsmiths absicht ist allerdings so klar, dass darüber kein wort zu verlieren ist. Ich habe mich nur dagegen gewandt, dass der streit über monogamie höchst unwahrscheinlich ist, da Wilmot, der Primroses alter freund und auch geistlicher ist, schon drei frauen gehabt hat. Primrose hätte also längst mit ihm darüber sprechen müssen, 
erwähnt er doch sogar, was andere freunde über seine theorie denken.

Von Wilmots geiz erfahren wir nach N. schon hier am ende des zweiten kapitels, nicht, wie ich gesagt hatte, erst im 31.; allein die thatsache, dass ihn der vermögensverlust endgiltig bestimmt, die verlobung aufzuheben (nachdem er doch schon vorher sufficiently inclined dazu war), beweist zwar seine prudence, d. h. seine weltklugheit, in etwas tadelndem sinne, aber doch noch lange nicht die immoderate passion for wealth, von der wir später hören. Sogar Primrose hat etwas von jener prudence, wiederholt spricht er aus, dass er Burchell als einen mann von zerrüttetem vermögen nicht als schwiegersohn haben wolle.

Wenn N. endlich sagt: „So hat auch Fischer die liebesgeschichte zwischen Georg und Arabella missverstanden", so bleibt er für diese behauptung jeden beweis schuldig. Er erklärt den widerspruch nicht, der darin besteht, dass zu anfang das verhältnis endgiltig gelöst wird, dass sich Georg demgemäss (nach des dichters absicht drei jahre lang) in keiner weise um Arabella kümmert und ihr dann doch vorgeworfen wird, sie habe ihr versprechen gebrochen. Nähme man ein geheimes einverständnis an, wovon nichts gesagt ist, so wären Georgs verhalten, als er bei den Arnolds mit ihr zusammentrifft, und Arabellas verlobung mit Thornhill ganz unbegreiflich.

Für die gesamthandlung legt $\mathrm{N}$. wert auf die bekannte vergleichung mit der geschichte Hiobs. $\mathrm{Zu}$ beachten ist, dass es sich dabei um das aufzeigen einer ähnlichkeit handelt, nicht um eine quelle.

Es bleibt mir noch ülbrig, über einige episoden, das milieu und den titel zu sprechen.

$\mathrm{N}$. hat eine reihe von episoden mit ihren quellen, wie ich sie angegeben hatte, gleichfalls aufgeführt, aber auch neues gebracht. Sicherlich hat er darin recht, dass die hauptquelle für den pferdeverkauf Primroses in einer ganz ähnlichen episode im zweiten kapitel des ersten buches von Gil Blas zu suchen ist. Ich füge hinzu, dass gewiss auch eine szene im Peregrine Pickle (kap. VIII) gewirkt hat, wo Trunnion für seine beiden pferde einen lächerlich geringen preis erhält, 
weil es der käufer versteht, die tiere als erbärmliche klepper hinzustellen. Ebenso zeigt N., dass Primroses gang zu Thornhills schlosse (XVIII 81), wo er nachricht über Olivia zu erhalten hofft, in einer szene der Pamela (I 99) sein vorbild hat. Auch das scheint mir richtig, dass für die darstellung von Primroses aufenthalt im gefängnis die schilderungen von Bunyans gefängnisleben von bedeutung gewesen sind.

Dagegen kann ich seiner vermutung über das vorbild für den rauhen empfang Olivias seitens ihrer mutter nicht beistimmen. 1752 verliess Goldsmith seine heimat, wohl beritten und mit geld versehen, um nach Amerika zu gehen, kam aber bald ganz mittellos auf einem elenden gaul zurück, worauf ihn seine mutter hart empfing. Dass dieses tragikomische erlebnis auf die tief tragische geschichte Olivias gewirkt haben soll, scheint mir sehr unwahrscheinlich. N. hat nach einem vorbild gesucht, weil ihm die härte Deborahs nicht $\mathrm{zu}$ ihrem charakter $\mathrm{zu}$ stimmen schien. Ich hatte in dieser härte einen reflex des verhaltens der Harlowesshen familie gegen Klarissa erblickt, glaube aber nicht, dass Deborah hier ihrem charakter untreu wird. Im gegenteil scheint mir die bemerkung, mit der Goldsmith das benehmen der pfarrerin erklärt, auf einer feinen und (wenigstens für frauen dieser art) wahren beobachtung zu beruhen: women have a much stronger sense of female error than men.

Ich füge ein paar kleinigkeiten hinzu. Auf die anwerbung Georgs nach Westindien kam Goldsmith durch seinen bruder Charles, der, als er ihn in London verliess, dorthin ging.

Im zehnten kapitel des $\mathrm{V}$. of $\mathrm{W}$. findet sich die lustige episode, dass die familie, um sich den beiden damen recht vornehm zu präsentieren, auf zwei pferden zur kirche reitet (dass man die ackergäule dazu benutzt, stammt, wie ich s. 161 gezeigt hatte, aus Amelia), aber durch die böswilligkeit der tiere nicht zum ziele gelangt, so dass man sie in der kirche vergeblich erwartet. Ein ganz ähnliches motiv findet sich im Peregrine Pickle (kap. VIII). Trunnion hat sich und seinen freund beritten gemacht, um der in der kirche versammelten hochzeitsgesellschaft möglichst stattlich zu erscheinen. Sie erreichen jedoch die kirche nicht, da die beiden tiere mit den des reitens ungewohnten freunden durchgehen.

N. nimmt wie ich die schilderung Wilsons im Joseph 
Andrews als vorbild für das milieu unseres romanes an. Ich füge noch hinzu, dass auch die Wilsons überaus gastfreundlich und wohlthätig sind, dass sie arme und kranke unterstützen und unter den nachstellungen eines bösen Squires zu leiden haben. Endlich sind sie aufs land gezogen, nachdem sie einen grossen teil ihres vermögens verloren haben, ganz wie in der Amelia Booth mit seiner frau - das ist vielleicht für den umzug der pfarrerfamilie mit von einfluss gewesen.

N. tadelt (s. 86), dass ich auch im titel des romans, der ja so schlecht passt, die oberflächliche arbeitsweise des dichters zu erkennen geglaubt habe; der grund für die titelbezeichnung sei uns eben nur bisher unklar. Die schwierigkeit sei gelöst, wenn es sich bestätige, dass Goldsmith auf wirkliche verhältnisse bezug genommen habe, wenn er etwa, wie es in dem wunderlichen berichte des Amerikaners Curwen heisst, einen wirklichen pfarrer von Wakefield zum vorbild gehabt hätte.

Das ist eine heitere kleine verirrung. N.'s meinung ist mit einiger übertreibung diese: ein dichter lernt in einem orte A. einen pfarrer kennen. Er schreibt einen roman, worin er züge von diesem manne benutzt, ihn aber zu einem arzt macht und lässt den roman in dem orte B. spielen. Diesem buche, dessen held also ein arzt in B. ist, darf dann der dichter mit vollem recht den titel: "der pfarrer von A.“ geben!

Gewiss mag man sich mit der hoffnung trösten, dass wir den titel, den wir nach 150 jahren nicht verstehen, vielleicht später noch verstehen werden, der litterarhistoriker jedoch verlangt, dass der titel aus dem werke selbst heraus verständlich ist. Sollte sich sicher herausstellen, dass Goldsmith wirkliche verhältnisse benutzt hat, so wäre das ganz interessant, aber es würde nichts an der thatsache ändern, dass der titel nicht passt. Nach meiner festen überzeugung hat Goldsmith einfach vergessen, dass die familie umgezogen ist, er hat gemeint, sie sei noch in Wakefield. Diese annahme wird mir dadurch bestätigt, dass der unbefangene leser in der regel den umzug gar nicht beachtet (auch Goethe glaubt, der roman spiele in Wakefield), vor allem aber, weil für solche vergesslichkeiten Goldsmiths so zahlreiche analogien vorhanden sind. Meine annahme allein erklärt den widerspruch, dass der titel so schlecht passt, obgleich gerade 
Goldsmith so viel wert auf einen treffenden titel zu legen pflegte: der titel Vicar of Wakefield passte vortrefflich, wenn die ganze geschichte sich in Wakefield abspielte, und das eben glaubte Goldsmith. Wenn er es nicht geglaubt hätte, wie hätte er dann die überschrift des 12. kapitels mit dem satze beginnen lassen können: 'Fortune seems resolved to humble the Family of Wakefield?'

N. glaubt (s. 99) wohl mit recht, dass die durch den besuch seines bruders Charles in Goldsmith wach gerufene sehnsucht nach der heimat als das konzeptionsgefühl $\mathrm{zu}$ betrachten ist. Auch er meint, wie ich schon gesagt hatte, dass die erinnerung an die heimat, an seinen vater und bruder auf die schilderung des familienlebens im ersten teile gewirkt hat, dass ihm dann unbewusst Adams vorschwebte und endlich die äussere handlung im wesentlichen aus drei grossen romanen übernommen wurde.

Man gestatte mir noch einige abschliessende bemerkungen. Was haben wir durch die letzten untersuchungen für das verständnis unseres dichters neues gelernt? Ich will versuchen, diese frage zu beantworten, um zugleich meine früheren darlegungen meiner jetzigen auffassung gemäss $\mathrm{zu}$ ergänzen.

Wir haben gefunden, dass der V. of W. in zweierlei hinsicht eine ganz ungewöhnliche erscheinung ist: zuerst haben uns die sehr starken anlehnungen an vorbilder überrascht, dann fanden sich (wie man zum teil schon wusste) überaus zahlreiche unwahrscheinlichkeiten und unebenheiten mannigfacher art. Betrachten wir zunächst den ersten punkt, Goldsmiths auffällige unselbständigkeit.

Dass der dichter, besonders der dramatiker, ein öfter behandeltes problem wieder aufnimmt und es auf seine eigene weise löst, wo es dann allein auf das wie, die ausführung, nicht auf das was, den stoff, ankommt; dass sich in einer dichtung aufs deutlichste die fäden erkennen lassen, die sie mit dem voraufgegangenen verknüpfen; dass von den verschiedensten seiten her einzelne anregungen gewirkt haben alles das ist nicht auffällig, eher die regel, das würde den V. of W. nicht als ausserordentlich erscheinen lassen. Das ausserordentliche besteht vielmehr darin, dass in unserem roman, und zwar zuweilen bis ins kleinste getreu, charaktere, 
grosse teile der handlung und zahlreiche episoden aus vier grossen romanen vereinigt sind, derart, dass keine wichtige person, keine der drei haupthandlungen, kaum ein wichtiges motiv ganz von litterarischer tradition frei ist. Auch wenn wir in betracht ziehen, dass die figur des pfarrers wirklich geschickt und selbständig weiter entwickelt ist, so bleibt doch des unselbständigen genug, um den eindruck eines gegewissen mangels an erfindungsgabe des dichters zu erwecken. Es fragt sich, ob wir es hier mit einer zufälligen, allein beim Vicar auftretenden erscheinung $\mathrm{zu}$ thun haben, oder ob es sich um einen Goldsmith überhaupt eigentümlichen zug handelt. Ist das letztere der fall, so muss sich ein wenigstens ungefähr ähnliches bild auch in den beiden lustspielen zeigen, als seinen einzigen schöpfungen ausser dem roman, in denen eine sorgfältig durchgeführte charakterzeichnung und handlung notwendig sind.

Im Good-Natured Man haben wir einen neffen und onkel im mittelpunkt der handlung wie im V. of W. In diesen beiden personen finden wir Burchell mit der bei seiner jugend unmöglichen entwickelung wieder - eine geschickte selbstnachahmung. Der neffe ist genau der frühere Burchell: 'he loves all the world' heisst es von dem einen, 'he loved all mankind von dem andern. Jedes fremde leid rührt den jungen Honeywood, er kann an keinem wahren oder erheuchelten unglück vorübergehen, ruiniert sich daher völlig durch seine krankhafte freigebigkeit und wird sich selbst verächtlich genau wie Burchell es von sich erzählt. Wie dieser ist er überaus leichtgläubig und lässt sich durch den schwätzer Lofty täuschen wie Burchell durch Thornhill; auch die entdeckung erfolgt in ganz ähnlicher weise. Bei der flucht des einen liebespaares gerät er trotz seiner guten absichten ebenfalls durch einen brief, der in falsche hände kommt und missverstanden wird, in den schmählichsten verdacht, der ihm heftige beschimpfungen zuzieht, ganz wie Burchell. Aber es wird uns nicht nur im oheim gezeigt, was aus dem neffen werden könnte, sondern es wird uns dessen entwickelung wirklich vorgeführt und gut begründet.

Der oheim, Sir William Honeywood, ist ebenso wie Sir William Thornhill der beste der menschen, abgeklärt und wohlwollend. Auch er tritt erst als einfacher mann verkleidet 
auf, giebt sich zuletzt zu erkennen und bringt die entscheidung. Auf diese lustspielfigur des oheims, der das thun seines neffen überwacht, hat auch litterarische tradition gewirkt.

Honeywoods braut, Miss Richmond, erinnert in manchem an Arabella Wilmot. Sie wird mit einem ungeliebten freier bedroht, hat aber schon gewählt. Zum schluss bietet sie sich dem geliebten selbst an, da dieser nicht an ihre liebe $\mathrm{zu}$ glauben wagt. Genau so handelt Arabella Georg gegenüber. Honeywood drückt seine freudige überraschung mit ähnlichen worten aus wie Georg.

Croaker ist zum teil nach einer gestalt des Citizen of the World gebildet; in dem streben nach aufrechterhaltung seiner autorität in der familie ähnelt er Primrose, dessen untrüglichen weisheitsspruch (heaven send we be all better this day three months) er wiederholt verwendet. Seine rolle gleicht der Wilmots; auch ihn bestimmen nur pekuniäre rücksichten bei der heirat seines kindes, auch er ist sogleich mit der mässigeren partie einverstanden, nachdem der betrüger Lofty entlarvt ist (wie im V. of W. Thornhill) und Sir William dafür eintritt. Seine frau hat dasselbe drollige streben nach vornehmen bekanntschaften wie Deborah.

In Lofty endlich ist Tibbs aus dem Citizen of the World wiederholt; seine prahlereien erinnern auch an die der beiden damen im Vicar, seine erkenntnis, dass der erfinder der kunst des wahrheitsprechens doch ein recht gescheiter kerl gewesen sein müsse, an die einsicht Jenkinsons, dass simpelste ehrlichkeit weiter bringe als die verschlagenste unredlichkeit. Jenkinson wird ohne genügende motivierung plötzlich zum ehrlichen manne und bewährt sich als solcher: dieser fehler ist hier vermieden, Loftys wandlung ist sehr gut begründet und in ihren folgen nur angedeutet.

Wir sehen jetzt schon, wenn Goldsmith einmal eine glückliche figur und ein ansprechendes motiv gefunden hat, so verwendet er es noch öfter in mannigfacher variation. $\mathrm{Zu}$ weilen nimmt er ein von ihm schon angedeutetes problem wieder auf und löst es wirklich.

Diese selbstnachahmung wird uns in dem zweiten lustspiel noch viel deutlicher.

Für dieses nahm Goldsmith aus seinem leben ein heiteres 
abenteuer, aus einer quelle eine lustige figur und einige kleinigkeiten - im übrigen ahmte er meist sich selbst nach. Die anlage beider stücke ist sehr ähnlich; hier wie dort acht handelnde personen, ein ehepaar, zwei liebespaare, ein alter herr und eine lustige person. Von dem ehepaar ist einmal der mann, das andere mal die frau berechnend, geldgierig und von ausgeprägt komischer wirkung, der andere teil aber vernünftig und sympathisch. In beiden familien lebt ein reiches mündel und ein grosser teil der handlung dreht sich darum, dass dies mündel hier vom ehemann, dort von der frau für den eigenen sohn bestimmt, dass aber niemand von den beteiligten mit der geplanten verbindung einverstanden ist. Nun existiert eine letztwillige verfügung, wonach das mündel hier die hälfte, dort das ganze vermögen an die familie des vormundes verlieren soll, wenn es diese partie ausschlägt. Das mündel, Miss Richmond im ersten, Miss Neville im zweiten lustspiele, ist schon verliebt, jene in Honeywood, diese in Hastings. Während im Good-natured Man das ehepaar nur ein kind, einen sohn, hat, der also einerseits das mündel heiraten soll, anderseits schon liebt, so ist hier noch eine tochter vorhanden. Der sohn hat dann die rolle, wider willen den freier des mündels zu spielen, die tochter liebt den jungen Marlow. Etwas ferner steht der handlung ein alter herr, hier Sir William Honeywood, dort Sir Charles Marlow, der erst zuletzt zu gunsten seines sohnes oder neffen eingreift, als dieser in seiner schüchternheit es aufgiebt, die zuneigung des mädchens $\mathrm{zu}$ gewinnen und fliehen will. Beide male übernimmt das mädchen die aktive rolle und bringt den ängstlichen liebhaber zur erklärung.

Das andere paar, das sich seit langem kennt, plant, da einem von ihnen eine verhasste heirat droht, eine flucht nach Schottland, um sich dort trauen zu lassen. Diese flucht wird noch rechtzeitig durch einen brief entdeckt, der in unrechte hände gelangt; die flüchtlinge glauben sich verraten von dem, der sie am eifrigsten unterstützt hat, hier Honeywood, dort Tony Lumpkin. Natürlich ist der ausgang der, dass nicht nur beide paare zum ziel ihrer wünsche kommen, sondern dass auch den mündeln der vermögensverlust erspart bleibt, da nicht sie, sondern der ihnen bestimmte gemahl die vorgeschlagene partie ablehnt. - In beiden stücken finden 
sich zwei ausgesprochen komische personen, hier Croaker und Lofty, dort Mrs. Hardcastle und Tony Lumpkin.

Man sieht, Goldsmith hat in ausgedehntem masse motive des ersten lustspieles im zweiten wiederholt, er hat nicht so sehr neues erfunden, als aus vorhandenem material mit dem grössten geschick immer wieder neues geformt. Und dass überhaupt bei so grossen übereinstimmungen ein wirklich eigenartiges und vortreffliches zweites stück herauskommen konnte, das zeigt schon, wie hervorragend sein talent für die ausführung im einzelnen ist. Thatsächlich sind die charaktere, die durch so viele fäden an die verschiedensten früher verwandten geknüpft sind, doch als ganze meist in der glücklichsten weise selbständig gestaltet, die wiederholten motive (zu denen doch auch manches jedem stücke eigentümliche kommt) sind so geschickt und humorvoll durchgeführt, und es findet sich eine solche fülle von heiteren szenen und überwältigend drolligen stellen im dialog, dass man unmöglich die selbstnachahmung Goldsmith für zu weitgehend erachten kann.

Wenn es gewiss ist, dass sich in den verschiedensten werken jedes dichters gewisse grundzüge und ideen immer wieder erkennen lassen, die vielleicht das innerste wesen der künstlerischen persönlichkeit am deutlichsten zeigen, so bleibt es doch ebenso gewiss, dass Goldsmith mit einem ungewöhnlich geringen aufwande von figuren und motiven auskommt. Halten wir nun die auffälligen entlehnungen im roman zusammen mit den starken nachahmungen in den lustspielen und erinnern wir uns der thatsache, dass selbst für kleinere sachen, einzelne essays, gedichte und dergl. sich oft die bestimmtesten anregungen nachweisen lassen (manches wird im laufe der zeit noch hinzukommen), dass sich im Citizen of the World und den essays manche später verwandte figur schon vorgebildet findet, endlich dass man gewisse lieblingsgedanken ausserordentlich oft antrifft, so müssen wir einen gewissen mangel an erfindungsgabe als einen für das verständnis der künstlerischen eigenart Goldsmiths wesentlichen zug erkennen.

Das zweite auffällige im V. of W. sind die zahlreichen unwahrscheinlichkeiten und direkten widersprüche, auf die ich in meiner früheren arbeit hingewiesen habe und deren 
zahl sich leicht noch vermehren liesse. Diese versehen, die sich meist aus der übernahme mehrerer fremder handlungen erklären, waren nur dadurch möglich, dass Goldsmith sein augenmerk $\mathrm{zu}$ oft nur auf die szene gerichtet hielt, mit der er sich gerade beschäftigte und nicht genügend auf das ganze dachte. Es lag ihm dann immer nur an der erreichung des nächstliegenden zieles, an einer einzelwirkung, nicht an der einheitlichkeit des ganzen. Der erste satz der vorbemerkung trifft hier völlig $\mathrm{zu}$ : es sind hundert fehler vorhanden und hunderterlei könnte man sagen um zu beweisen, dass es schönheiten sind, d. h. es sind fehler im zusammenhange des romans, für sich betrachtet aber schönheiten.

Ich will noch einmal einige von den zahlreichen charaketristischen fällen anführen. Sophia und Olivia sind im ersten teile fast ganz gleich behandelt, Sophia ist ebenso gefallsüchtig und oberflächlich wie Olivia. Die szenen, in denen mutter und töchter zusammen gegen den vater operieren, gehören zu den wirkungsvollsten humoristischen szenen des romanes: zweifellos wäre diese wirkung stark beeinträchtigt worden, wenn Sophia sich überlegen von dem treiben der beiden anderen ferngehalten hätte. Um dieser wirkung willen kam es Goldsmith nicht darauf an, Sophia gänzlich aus ihrer rolle fallen $\mathrm{zu}$ lassen und so überhaupt auf eine einheitliche charakterisierung dieser figur zu verzichten.

Goldsmith wollte seine eigenen reiseerlebnisse in poetischer verklärung und umgestaltung in den roman verflechten in der interessanten erzählung Georgs. Aber er kümmerte sich nicht darum, dass sie zeitlich nicht in den zusammenhang passt, dass Georgs bekanntschaft mit Thornhill und die daraus folgende darlegung seines wirklichen charakters vor Arabella Wilmot mit vorhergehendem und folgendem in widerspruch stehen.

Dass Jenkinson, der den pfarrer und Moses betrogen hat, identisch erscheint mit Thornhills helfershelfer, der im stande und bereit ist, die familie sehr wesentlich zu unterstützen, giebt eine wirksame überraschung, und die szene, in der er an seiner eingelernten griechischen redensart erkannt wird, ist von köstlichem humor; aber Goldsmith hat übersehen, dass diese verschiedenen rollen nicht ohne weiteres einem charakter zugeteilt werden können.

Anglia. N. F. XV. 
Es liessen sich noch viele andere fälle nennen, die stets dasselbe gesicht zeigen: um einer einzelwirkung willen nimmt der dichter auch grobe mängel mit in kauf. So ausgeprägt findet sich diese erscheinung nur im $\mathrm{V}$. of $\mathrm{W}$., in den lustspielen sind nur ganz vereinzelte beispiele zu finden, die allerdings genau so zu beurteilen sind. Der unterschied stammt daher, dass Goldsmith für das lustspiel eine ungleich grössere begabung besass als für den roman. Soviel lässt sich immerhin auch allgemein sagen, dass es Goldsmith sehr oft mehr an einer einzelnen szene liegt, als an einer sorgfältig durchgeführten handlung und charakterzeichnung, mehr an der künstlerischen wahrheit des einzelnen als an der absoluten wahrscheinlichkeit des ganzen.

Dieser mangel erklärt sich daraus, dass dem dichter (wie dem menschen) Goldsmith jene besonnene überlegung und abwägende sorgfalt abging, deren auch der grösste künstler bedarf; in genialischer unbefangenheit konnte er es wagen, das unmögliche für wahr auszugeben, weil seine begabung stark genug war, auch das unmögliche so liebenswürdig einzukleiden, dass es plausibel wurde. Theoretisch billigt Goldsmith diese verstösse gegen die wahrscheinlichkeit natürlich nicht, er verlangt vom dichter durchaus 'truth' und 'probability'; aber beim V. of W. sucht er sie zu entschuldigen, einmal in der vorbemerkung, dann wohl auch in den worten, die er Burchell, der ja öfter seine meinung ausspricht, in den mund legt (XV 65/66): "The reputation of books is raised, not by their freedom from defect, but the greatness of their beauties."

Ich fasse zusammen: in den selbständigen werken des dichters zeigt sich ein gewisser mangel an erfindungsgabe und oft eine auffällige gleichgiltigkeit gegenüber der realen möglichkeit des dargestellten. Dagegen versteht er es meisterhaft, jedem stoffe das gepräge seines geistes aufzudrücken; seine stärke liegt in seinem talent für die poetische ausführung im einzelnen, die im grunde doch das wesentliche ist. Diese begabung kann sich ganz rein überall da zeigen, wo keine ausgeführte fabel und charakterzeichnung nötig ist, sondern wo es sich um durchführung einer einzelnen idee handelt; so im Traveller und Deserted Village, wo der dichter schildernd leicht von einem gegenstande zum andern 
gleiten kann, so in zahlreichen essays und kleinen gedichten.

Worin nun der wunderbare zauber der darstellungsweise Goldsmiths begründet liegt, das lässt sich schwerlich ganz fassen und aussprechen, ich kann nur versuchen einiges anzudeuten. Bekannt ist des dichters vorliebe für das kunstmittel des kontrasts, das er besonders im V. of W. unzählige male wirkungsvoll verwandt hat. So wechseln, um nur ein paar grosse züge anzuführen, im ersten teile des romans ziemlich regelmässig zwei reihen von szenen: ein gezwungener, der pfarrerfamilie nicht gemässer ton herrscht in den Thornhillszenen, idyllische ruhe, natürlichkeit und zufriedenheit, wenn Burchell auftritt. Nach Burchells entfernung folgt eine kurze zeit der unruhe unter dem einflusse Thornhills, dann die reine auflösung alles ehrgeizigen, unbehaglichen treibens in der wundervollen szene des 17. kapitels, die den höhepunkt des ersten teiles bildet. Mit der höchsten kunst ist diese szene ausgeführt. Der böse geist, der soviel sorge verursacht hat, scheint unschädlich gemacht, der pfarrer, der eine gewisse schuld gegen Williams auf sich geladen hatte, fühlt sich wieder ganz frei, gesichert und ruhig liegt die zukunft da und nun bricht das furchtbarste unglück herein. In der schilderung der wirkung dieser nachricht auf den pfarrer, des ringens zwischen dem natürlichen menschen und dem christen in ihm, hat Goldsmith durch die höchste lebenswahrheit die höchste poetische schönheit erreicht. Die thatsache, dass die anregung für diese szene von Fielding ausgegangen ist, verliert dem gegenüber jede bedeutung. Es folgt dann ein unglück auf das andere, und diese schweren schläge erst setzen Primrose in stand, sich zu der reinen höhe der kerkerpredigt aufzuschwingen, die den höhepunkt des zweiten teiles bildet. Nun er sich gänzlich über das irdische erhoben hat, tritt die glückliche wendung ein.

$\mathrm{Zu}$ dem eigensten wesen Goldsmiths gehört gewiss auch sein humor, der sich am glänzendsten im V. of W. zeigt. Richardson hat fast gar keinen humor, wohl aber Fielding, Smollett und Sterne. Während diese jedoch vielfach zur satire, zur karikatur und zum derb komischen greifen, ist Goldsmiths humor (ausser im Citizen of the World und einzelnen essays, wo eine bestimmte tendenz vorlag) ganz 
tendenzlos, natürlich und niemals niedrig. Besonders der erste teil des romanes ist durchleuchtet von diesem sonnigen humor, der unwiderstehlich eine heitere, wohlthuende wirkung übt, und zwar nach Goldsmith selbst deshalb, weil er dem leser das gefühl der eigenen überlegenheit giebt. Die meisten der kleinen züge, die jedem leser unvergesslich bleiben, sind humoristisch - von der drolligen naivetät des ersten satzes und der bedeutungsschweren grabschrift auf die pfarrerin bis zu Wilmots geistreichem witz über Moses. Wie ist das humoristische an Primrose und Moses aus der derbkomischen sphäre bei Fielding ins liebenswürdig-heitere emporgehoben! Da ist eine andere gestalt vorwiegend humoristisch, ohne dass in der quelle auch nur eine andeutung dafür vorhanden gewesen wäre, nämlich Deborah. Ihre sorglichkeit, ihr ehrgeiz, ihre eitelkeit, ihre eingebildetheit und ihre rednerischen talente - alles eigenschaften, die frau Adams ebenso gut hat oder haben könnte, sie sind mit dem köstlichsten humor durchtränkt und hierin liegt Goldsmiths selbständiges verdienst um diese figur. So unbedeutende personen wie die Flamboroughs, mit welcher fülle von humor sind sie umkleidet durch einige wenige züge, und wie erfreulich bleibt dieser humor, der uns keinen augenblick die herzensgüte dieser familie verdunkelt! - Der erste teil ist weit stärker humoristisch als der zweite, er ist ja auch der selbständigste und gelungenste teil.

Hiermit ist Goldsmiths eigenart freilich durchaus nicht erschöpft, auch ernste szenen gelingen ihm und besonders gut liegt ihm ein leise melancholischer ton, wie in einigen szenen des V. of W., im Traveller und Deserted Village.

$\mathrm{N}$. bestimmt am schluss Goldsmiths litterarische stellung: dahin, dass er auf seiten des Richardsonschen romanes stehe. Mir dagegen scheint Goldsmiths geschichtliche bedeutung darin $\mathrm{zu}$ bestehen, dass er die beiden feindlichen strömungen, den aus den moralischen wochenschriften entstandenen roman Richardsons und den auf spanischen und französischen quellen beruhenden roman Fieldings im V. of W. vereinigt. Ganz äusserlich weist darauf schon seine gleichmässige benutzung beider hin. Bei Richardson finden wir eine durchsichtige, straffe komposition, langsames fortschreiten der handlung, genaueste zerlegung der charaktere und eingehende milieu- 
schilderung, strengen sittlichen ernst, überhaupt ernste lebensauffassung, keinen humor - bei Fielding eine verwickeltere, weniger durchsichtige, etwas lockere komposition, schnell fortschreitende handlung, weniger ausführliche, aber immer sehr gegenständliche charakter- und milieuschilderung, leichtere sittliche auffassung, ausgesprochenen optimismus und derben humor. Goldsmith hat wie Richardson im ersten teile verhältnismässig einfache und klare komposition, langsames fortschreiten der handlung, eingehende milieuschilderung; wie Fielding unïbersichtlichere komposition und schnell schreitende handlung im zweiten teil, einfachere charakterzeichnung, ausgeprägt heitere lebensauffassung und humor. Seine sittlichen anschauungen stehen etwa in der mitte zwischen beiden. Er steht beiden nach an erfindungsgabe, an geschick in der verknüpfung der äusseren ereignisse, die oft mangelhaft ist und vielfach in der charakterzeichnung (natürlich nicht bei figuren wie Primrose und Deborah). In anderer hinsicht geht er über die vorgänger hinaus; aber nicht dadurch, dass er von der charakterzeichnung zur charakterentwickelung übergeht, wie N. will. Diese behauptung, die wenn sie zuträfe, doch von grosser bedeutung wäre, stützt sich nach N. selbst einzig auf die entwickelung Deborahs, und ich habe gezeigt, dass davon keine rede sein kann. Goldsmiths verdienst besteht vielmehr, wie man auch immer gesehen hat, in der einführung des idyllischen familienromanes und dann in seiner gefälligen darstellungsweise.

Goldsmith stützt sich auf zwei einander direkt gegenüberstehende gruppen von romanen, die auf entgegengesetzten, unvereinbar scheinenden lebensanschauungen beruhen. Goldsmith fühlt das gemeinsame beider richtungen, und indem er sich von der drückend schwerfälligen, tendenziösen, oft unnatürlichen art der einen ebenso fermhält wie von der ebenfalls tendenziösen, derben art der anderen, gelingt es ihm, das gebiet des einfachen familienlebens in ganz tendenzloser, leicht flïssiger, heiterer und doch von sittlichem ernst getragener darstellung für den roman zu gewinnen. Wenn der $\mathrm{V}$. of W. nicht völlig gegliickt ist, so ist das, was gelungen ist, doch das wesentliche; wenn sich kaum ein zug findet, für den sich nicht irgendwelche mehr oder weniger bedeutsame anregung nachweisen liesse, so ist die vereinigung und 
554 WILLI FISCHER, ZU GOLDSMITHS VICAR OF WAKEFIELD.

ausgestaltung dieser züge doch durchaus neu. Das wichtigste aber ist, dass der völlige genuss und das völlige verständnis des V. of W. in keiner weise an das studium einer tendenz, bestimmter örtlicher oder zeitlicher bedingungen d. h. veraltbarer dinge, geknüpft ist, sondern dass in rein poetischer weise rein menschliche angelegenheiten behandelt werden; daher ist der roman immer jung geblieben, während Klarissa, Tom Jones und Roderick Random ausgesprochen bücher des 18. jahrhunderts sind.

WitTENBERG.

Willi Fischer. 